\title{
OPTIMASI PENUGASAN MENGGUNAKAN METODE HUNGARIAN
}

\section{PT HANA TEXT}

\author{
Risqiati $^{1)}$, Indrayanti ${ }^{2)}$, Nur Ika Royanti ${ }^{3)}$ \\ Program Studi Teknik Informatika, Manajemen Informatika, Sistem Informasi \\ STMIK Widya Pratama, Indonesia. \\ Email: risqiati24@gmail.com ${ }^{1}$, indrayanti3214@gmail.com ${ }^{2}$, ikaroyant@gmail.com ${ }^{3}$
}

\begin{abstract}
Abstrak
Dalam semua proses produksi, ketepatan dalam pengupahan adalah yang sangat penting, sesuai dengan pekerjaan yang dikerjakan. Hal ini dimaksudkan agar tidak terjadinya over cost atau biaya yang tidak diperdiksi dalam hal pengupahan. Sedemikian pula yang terjadi di PT.Hana Text, pengupahan yang selama ini dilakukan melakui hasil perkiraan saja tanpa ada perhitungan yang wajar atau sesuai dengan jenis pekerjaan yang telah diselesaikan. Tentu saja kondisi ini bisa menimbulkan biaya tambahan yang sering kali tidak diketahui. Melalui metode Hungarian, persoalan di PT.Hana Text akan dicoba untuk diurai agar terjadi biaya upah minimum dari tenaga kerja yang tepat sesuai proses penugasannya. Dengan adanya 5 jenis tugas/pekerjaan yang dilakukan oleh pekerja, maka bisa dihitung upah minumnya dengan metode hungarian didapatkan hasil minimum biaya upah adalah 380 dari pengolahan matrik yang ada
\end{abstract}

Kata kunci: Metode Hungarian, upah minimum, biaya produksi, matrik

\section{Pendahuluan}

Di era globalisasi ini, banyak usaha yang memproduksi barang ataupun jasa. Produk yang dihasilkan suatu perusahaan harus bisa bersaing dengan produk lain. Sehingga perusahaan harus mengelola aspek produksi dengan menentukan tenaga kerja yang tepat sesuai dengan penugasannya. Sehingga bisa meminimumkan biaya upah produksi. Masalah penugasan tenaga kerja ini merupakan kasus yang sering ditemui dalam suatu perusahaan. Salah satu metode yang digunakan untuk penugasan adalah metode Hungarian (Sofinurriyanti 2018) (Idris Gautama So, Haryadi Sarjono, Robertus Tang Herman 2013) (Marline Paendong, Jantje D. Prang 2011). Metode Hungarian adalah metode yang digunakan untuk menentukan penugasan suatu tenaga kerja yang memodifikasikan baris dan kolom dalam matrik sampai muncul nilai nol, sehingga nantinya didapatkan hasil penugsan yang tepat untuk masing-masing tenaga kerja (Sofinurriyanti 2018) (Marisa Yulistiana, Diah Chaerani, Eman Lesmana 2015). Metode hungarian ini bisa digunakan untuk mengoptimasi penugasan tenaga kerja di PT. Hana Text.

PT. Hana Text adalah PT. yang bergerak di bidang produksi batik. antara lain membuat baju batik. Untuk memproduksi baju batik dibutuhkan proses penugasan pemutihan, penyablonan, pemotongan, jahit dan pengemasan / packing. Dari proses penugasan ini, akan dihitung untuk meminimalkan biaya upah tenaga kerja di PT. Hana Text.

Dari masalah itu, maka akan dibuatkan suatu optimasi penugasan menggunakan metode Hungarian di PT. Hana Text untuk membantu pimpinan dalam meminimalkan biaya upah tenaga kerja dilihat dari proses penugasan yang tepat untuk masing-masing tenaga kerja saat memproduski baju batik.

\section{Metode Penelitian}

Masalah yang dihadapi oleh PT. Hana Text adalah bagaimana meminimalkan biaya upah tenaga kerja sesuai dengan penugasan yang tepat. Dari data tenaga kerja sebanyak 5 tenaga kerja dengan upah dari setiap penugasannya yaitu 
pemutihan kain, penyaablonan, pemotongan, jahit dan pengemasan, kemudian diolah untuk mendapatkan informasi tentang biaya minimum upah dari tenaga kerja yang tepat sesuai dengan bidang penugasannya. Dalam melakukan penugasan tenaga kerja menggunakan metode hungarian dengan menghasilkan biaya upah minimum untuk tenaga kerja yang tepat.

Kerangka pemikiran dari penelitian ini adalah

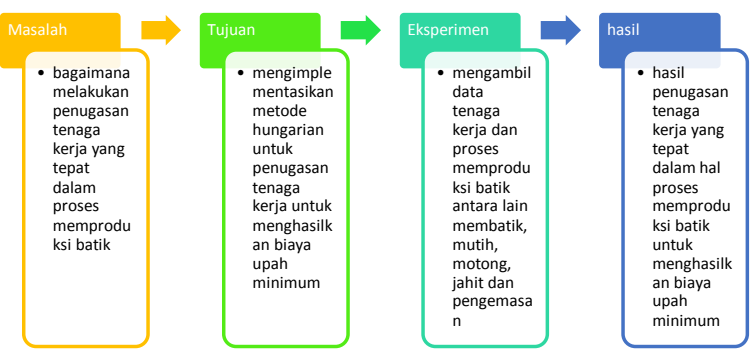

Gambar 1. Kerangka pemikiran penelitian

Dalam pemberian tugas kepada tenaga kerja di PT. Hana Text dengan tahapan yang harus dilaksanakan untuk memastikan mencapai hasil yang maskimal. Tahapan dari prosedur penelitian pertama dengan mengidentifikasi dan merumuskan masalah yang menjadi tujuan dari penelitian ini, dengan mengisi upah tenaga kerja berdasarkan penugasannya. Adapun langkah penelitian adalah sebagai berikut:

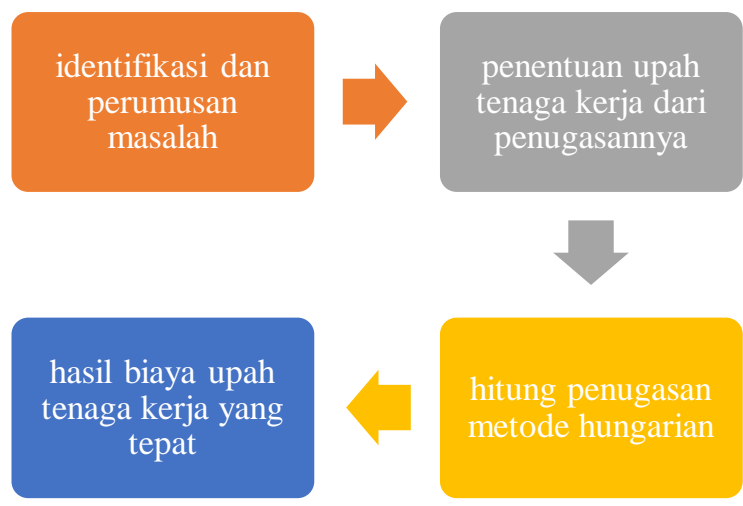

Gambar 2 Langkah Penelitian.

Berikut adalah langkah-langkah perhitungan metode Hungarian (Dwi Harini 2017) a. Mengurangi setiap elemen baris matrik dikurangi dengan setiap elemen terkecilnya.

b. Mengurangkan hasil dari nnilai setiap matrik dari langkah ke 1 dengan elemen .

c. Dengan menarik sejumlah garis minimum horizontal dan atau garis vertical untuk meliputi seluruh elemen bernilai 0 merupakan prosedur optimalisasi.

d. Pilihlah elemen yang paling kecil dari matriks yang dihasilkan oleh langkah tiga yang tidak melewati garis, dan gunakan elemen itu untuk mengurangi elemen yang dilewati garis sebanyak dua kali. Dan lakukan langkah ketiga berulangkali sampai didapat tabel optimum.

e. Terapkan tenaga kerja tersebut pada tugas yang sesuai

\section{Hasil dan Pembahasan}

Untuk penelitian ini menggunakan penghitungan manual dengan 5 tenaga kerja. Dengan variabel yaitu biaya upah tenaga kerja dengan 5 proses penugasan yaitu pemutihan, penyablonan, pemotongan, jahit dan pengemasan yang dijadikan sebagai acuan utnuk proses perhitungan. Berikut ini langkah-langkah penelitian yang dirinci sebagai berikut:

\subsection{Identifikasi dan Perumusan masalah}

Saat ini PT. Hana Text kesulitan dalam menentukan penugasan tenaga kerja yang tepat untuk meminimumkan biaya upah tenaga kerja. Penugasan tenaga kerja diperlukan agar PT. Hana text bisa mengetahui penugasan apa yang tepat untuk masing-masing tenaga kerja untuk bisa menekan biaya produksi yang tidak terduga

\subsection{Penentuan Penugasan Tenaga Kerja}

PT. Hana text melakukan pendataan tenaga kerja saat proses memproduksi batik. Adapun yang dijadikan perhitungan akhir dari penugasan 
metode Hungarian ini adalah biaya upah minimum dari tenaga kerja yang tepat sesuai proses penugasannya. Adapun datanya seperti tabel 1 dibawah ini

Tabel 1. Data upah tenaga kerja sesuai dengan penugasannya

\begin{tabular}{lrrlrr}
\hline & $\begin{array}{l}\text { Pemut } \\
\text { hanan }\end{array}$ & $\begin{array}{l}\text { Pemot } \\
\text { ongan }\end{array}$ & $\begin{array}{l}\text { Print } \\
\text { ing }\end{array}$ & Jahit & $\begin{array}{r}\text { Penge } \\
\text { masan }\end{array}$ \\
\hline Joyo & 80 & 120 & 70 & 60 & 100 \\
Tajab & 100 & 80 & 60 & 130 & 110 \\
Rosid & 80 & 70 & 50 & 110 & 120 \\
Want & & & & & \\
o & 60 & 130 & 60 & 140 & 90 \\
Arif & 130 & 110 & 100 & 90 & 150 \\
\hline
\end{tabular}

\subsection{Hitung Penugasan Dengan Metode Hungarian}

Dari data upah tenaga kerja sesuai dengan penugasannya, dipilih elemen terkecil dari setiap baris dari matrik biaya untuk mengurangi seluruh elemen dalam setiap baris yang disajikan pada tabel 2. Dalam hal ini, upah terkecil dari baris pertama adalah30 dari penugasan jahit.

Tabel 2. Hasil nilai upah minium dari baris pertama

\begin{tabular}{lrrrrr}
\hline & $\begin{array}{l}\text { Pemut } \\
\text { ihan }\end{array}$ & $\begin{array}{l}\text { Pemoto } \\
\text { ngan }\end{array}$ & $\begin{array}{l}\text { Prin } \\
\text { ting }\end{array}$ & $\begin{array}{l}\text { Jahit } \\
\text { Pen } \\
\text { gem } \\
\text { asan }\end{array}$ \\
\hline Joyo & 20 & 60 & 10 & 0 & 40 \\
Tajab & 40 & 20 & 0 & 70 & 50 \\
Rosid & 30 & 20 & 0 & 60 & 70 \\
Want & & & & & \\
o & 0 & 70 & 0 & 80 & 30 \\
Arif & 40 & 20 & 10 & 0 & 60 \\
\hline
\end{tabular}

Dari tabel 2, pilih elemen terkecil dari setiap kolom dari matrik untuk mengurangi seluruh elemen dalam kolom tersebut

Tabel 3. Hasil dari nilai upah minimum dari elemen kolom

\begin{tabular}{|c|c|c|c|c|c|}
\hline & $\begin{array}{l}\text { Pemut } \\
\text { ihan }\end{array}$ & $\begin{array}{l}\text { Pemoto } \\
\text { ngan }\end{array}$ & $\begin{array}{l}\text { Print } \\
\text { ing }\end{array}$ & Jahit & $\begin{array}{l}\text { Peng } \\
\text { emas } \\
\text { an }\end{array}$ \\
\hline Joyo & 20 & 40 & 10 & 0 & 10 \\
\hline Tajab & 40 & 0 & 0 & 70 & 20 \\
\hline Rosid & 30 & 0 & 0 & 60 & 40 \\
\hline Wanto & 0 & 50 & 0 & 80 & 0 \\
\hline Arif & 40 & 0 & 10 & 0 & 30 \\
\hline
\end{tabular}

Tabel 4. Test optimalisasi

\begin{tabular}{lrrrrr}
\hline & $\begin{array}{l}\text { Pem } \\
\text { utiha } \\
\text { n }\end{array}$ & $\begin{array}{l}\text { Pemot } \\
\text { ongan }\end{array}$ & $\begin{array}{l}\text { Print } \\
\text { ing }\end{array}$ & \multicolumn{2}{l}{$\begin{array}{l}\text { Jeng } \\
\text { emas } \\
\text { an }\end{array}$} \\
\hline Joyo & 20 & 40 & 10 & 0 & 10 \\
Tajab & 40 & 0 & 0 & 70 & 20 \\
Rosid & 30 & 0 & 0 & 60 & 40 \\
Wanto & 0 & 50 & 0 & 80 & 0 \\
Arif & 40 & 0 & 10 & 0 & 30 \\
\hline
\end{tabular}

Untuk revisi matrik, maka pada tabel 4 pilih elemen yang terkecil yang belum terliput garis untuk mengurangi elemen yang belum terliput, kemudian tambahkan dengan jumlah yang sama pada seluruh elemen yang mempunyai 2 garis saling bersilangan

Tabel 5. Hasil Revisi Matrik

\begin{tabular}{lrrrrr}
\hline & $\begin{array}{l}\text { Pemut } \\
\text { ihan }\end{array}$ & $\begin{array}{l}\text { Pemoto } \\
\text { ngan }\end{array}$ & $\begin{array}{l}\text { Print } \\
\text { ing }\end{array}$ & \multicolumn{2}{c}{$\begin{array}{l}\text { Peng } \\
\text { Jahit } \\
\text { anas }\end{array}$} \\
\hline Joyo & 10 & 49 & 10 & 0 & 0 \\
Tajab & 30 & 0 & 0 & 70 & 20 \\
Rosid & 20 & 0 & 0 & 60 & 30 \\
Want & & & & & \\
o & 0 & 50 & 0 & 80 & 0 \\
Arif & 30 & 0 & 10 & 0 & 20 \\
\hline
\end{tabular}


Dari tabel 5, pilih Prosedur optimalisasi kembali dengan menarik sejumlah minimum garis horizontal dan garis vertical untuk meliputi seluruh elemen bernilai 0 .

Tabel 6. Revisi Test Optimalisasi

\begin{tabular}{lcrlrl}
\hline & $\begin{array}{l}\text { Pem } \\
\text { utih } \\
\text { an }\end{array}$ & $\begin{array}{l}\text { Pemoto } \\
\text { ngan }\end{array}$ & \multicolumn{1}{l}{$\begin{array}{l}\text { Print } \\
\text { ing }\end{array}$} & \multicolumn{2}{c}{$\begin{array}{l}\text { Jeng } \\
\text { ema } \\
\text { san }\end{array}$} \\
\hline Joyo & 10 & 40 & 10 & 0 & 0 \\
Tajab & 30 & 0 & 0 & 70 & 20 \\
Rosid & 20 & 0 & 0 & 60 & 30 \\
Wanto & 0 & 50 & 0 & 80 & 0 \\
Arif & 30 & 0 & 10 & 0 & 20 \\
\hline
\end{tabular}

Bila jumlah garis sama dengan jumlah garis baris/kolom, penugasan optimal telah selesai, maka didapatkan hasil sebagai berikut:

Tabel 7. Hasil biaya upah Tenaga Kerja sesuai dengan penugasan yang tepat

\begin{tabular}{llrr}
\hline & & $\begin{array}{c}\text { Alternatif } \\
\text { Penugasan }\end{array}$ & $\begin{array}{c}\text { Alternatif } \\
\text { P }\end{array}$ \\
\hline Joyo & $:$ & 100 & 100 \\
Tajab & $:$ & 60 & 80 \\
Rosid & $:$ & 70 & 50 \\
Wanto & $:$ & 60 & 60 \\
Arif & $:$ & 90 & 90 \\
\hline
\end{tabular}

\section{Kesimpulan dan saran}

Bahwa hasil penugasan dari metode Hungarian ini didapatkan hasil minimum biaya upah adalah 380. Untuk penelitian berikutnya bisa ditambahkan variable waktu untuk menghitung kecepatan waktu penugasan.

\section{DAFTAR PUSTAKA}

Dwi Harini. "Optimasi Penugasan Menggunakan Metode Hungarian Pada CV. L\&J Express Malang (Kasus Minimasi)." INTENSIF Vol. 1 No. 2, 2017: 68-74.

Idris Gautama So, Haryadi Sarjono, Robertus Tang Herman. "Penerapan Metode Hungarian Pada Perusahaan Jasa (Kasus Minimum)." Binus Business Review, 2013: 812-820.
Marisa Yulistiana, Diah Chaerani, Eman Lesmana. "Penerapan Metode Hungarian Dalam Penentuan Penjadwalan Matakuliah Optimal (Studi Kasus : Departemen Matematika Universitas Padjajaran Semester Ganjil 20132014)." Jurnal Matematika Integratif, 2015: 4564.

Marline Paendong, Jantje D. Prang. "Optimasi Pembagian Tugas Karyawan Menggunakan Metode Hungarian." Jurnal Ilmiah Sains Vol 11 No. 1, 2011: 109-115.

Sofinurriyanti. "Analisis Penggunaan Metode Assignment Dalam Mengoptimalkan Penugasan Karyawan Untuk Setiap Departemen Pada Proses Produksi Ikan Teri Cryspi." Rekayasa, 2018: 104109. 